\title{
Effects of inspiratory muscle training on dyspnoea in severe COPD patients during pulmonary rehabilitation: controlled randomised trial
}

\author{
Marc Beaumont ${ }^{1}$, Philippe Mialon ${ }^{2}$, Catherine Le Ber ${ }^{1}$, Patricia Le Mevel ${ }^{1}$, \\ Loïc Péran ${ }^{1}$, Olivier Meurisse ${ }^{1}$, Capucine Morelot-Panzini ${ }^{3}$, Angelina Dion $^{4}$ and \\ Francis Couturaud ${ }^{5}$
}

Affiliations: ${ }^{1}$ Pulmonary Rehabilitation Unit, Morlaix Hospital Centre, EA3878, European University of Occidental Brittany, Morlaix, France. ${ }^{2}$ Pulmonary Physiology Unit, EA2438, European University of Occidental Brittany, University Brest Centre, Brest, France. ${ }^{3}$ Pulmonary and Reanimation Unit, Pitié Salpétrière Hospital, Paris, France. ${ }^{4}$ INSERM CIC 1412, University Hospital of Brest, Brest, France. ${ }^{5}$ Dept of Internal Medicine and Chest Diseases, EA3878 (GETBO), CIC INSERM 1412, University Hospital of Brest, European University of Occidental Brittany, Brest, France.

Correspondence: Marc Beaumont, GETBO, EA 3878, Pulmonary Rehabilitation Unit, Morlaix Hospital Centre, European University of Occidental Brittany, 29672 Morlaix CEDEX, France.

E-mail: marc.beaumontauniv-brest.fr

@ERSpublications

Inspiratory muscle training during pulmonary rehabilitation has no additional effect on dyspnoea http://ow.ly/950d30ggYdd

Cite this article as: Beaumont $\mathrm{M}$, Mialon $\mathrm{P}$, Le Ber C, et al. Effects of inspiratory muscle training on dyspnoea in severe COPD patients during pulmonary rehabilitation: controlled randomised trial. Eur Respir J 2018; 51: 1701107 [https://doi.org/10.1183/13993003.01107-2017].

ABSTRACT The benefit of inspiratory muscle training (IMT) combined with a pulmonary rehabilitation programme (PRP) is uncertain. We aimed to demonstrate that, in severe and very severe chronic obstructive pulmonary disease (COPD) patients, IMT performed during a PRP is associated with an improvement of dyspnoea.

In a single-blind randomised controlled trial, 150 severe or very severe COPD patients were allocated to follow PRP+IMT versus PRP alone. The evaluations were performed at inclusion and after 4 weeks. The primary outcome was the change in dyspnoea using the Multidimensional Dyspnoea Profile questionnaire at the end of a 6-min walk test (6MWT) at 4 weeks. Secondary outcomes were changes in dyspnoea using the Borg (end of the 6MWT) and modified Medical Research Council scales and in functional parameters (maximal inspiratory pressure (PImax), inspiratory capacity, 6MWT and quality of life). All analyses were performed on an intention-to-treat basis.

Dyspnoea decreased significantly in both groups; however, the improvement of dyspnoea was not statistically different between the two groups. We only found a statistically significant greater increase of PImax after IMT+PRP than after PRP alone.

In this trial including severe or very severe COPD patients, we did not find a significant benefit of IMT during PRP+IMT as compared to PRP alone on dyspnoea, despite a significantly higher improvement of PImax in the IMT group.

This article has supplementary material available from erj.ersjournals.com

Received: June 062017 | Accepted after revision: Oct 292017

This study is registered at www.ClinicalTrials.gov with identifier number NCT02074813

Support statement: This study was supported by the French Ministry of Health. Funding information for this article has been deposited with the Crossref Funder Registry.

Conflict of interest: None declared.

Copyright @ERS 2018 


\section{Introduction}

Pulmonary rehabilitation is an important component of chronic obstructive pulmonary disease (COPD) management $[1,2]$. During the past decade, several prospective trials have shown that pulmonary rehabilitation in COPD patients was associated with a decrease in COPD-related handicap and an improvement of quality of life. In addition, a reduction of mortality was suggested in one of these studies when pulmonary rehabilitation was performed early after an acute COPD exacerbation [3].

In most of these trials, the pulmonary rehabilitation programme included individualised exercise training, therapeutic education, respiratory physiotherapy, help with smoking cessation and nutritional and psychosocial coverage. Exercise training included both endurance and force lower-limb training associated with upper-limb training. In addition, the European Respiratory Society (ERS) consensus recommends inspiratory muscle training (IMT) in association with a usual pulmonary rehabilitation programme in patients with inspiratory muscle weakness. This recommendation is based on the results of several meta-analyses [4-6], which suggested a beneficial effect of IMT on dyspnoea, strength and endurance of inspiratory muscles and exercise capacity in the 6-min walk test (6MWT), particularly when the maximal inspiratory pressure $\left(P_{\operatorname{Imax}}\right)$ was $<60 \mathrm{cmH}_{2} \mathrm{O}$. However, the authors of the latest meta-analysis [6] suggested that the benefit of IMT performed during pulmonary rehabilitation on dyspnoea has not yet been demonstrated and the authors of the consensus about pulmonary rehabilitation specified that IMT during pulmonary rehabilitation remains questionable [1].

In a recent randomised trial [7], we found that performing IMT during pulmonary rehabilitation in COPD patients with a $P \operatorname{Imax}>60 \mathrm{cmH}_{2} \mathrm{O}$ did not result in a significant improvement of dyspnoea. However, we also found a trend towards a benefit of IMT in more severe COPD patients; in these patients, we hypothesised that strengthening the inspiratory muscles might produces a decrease in dynamic hyperinflation, which is a major mechanism involved in dyspnoea. However, our sample size was too small to be conclusive.

Thus, we conducted a randomised controlled trial comparing IMT with pulmonary rehabilitation versus pulmonary rehabilitation only in severe or very severe COPD patients. The primary objective was to demonstrate that IMT performed during pulmonary rehabilitation was associated with an improvement in the sensory component of dyspnoea at end of the 6MWT. Secondary objectives were to evaluate the effect of IMT on dyspnoea according to predefined strata $(P \operatorname{Imax})$ and on secondary end-points: quality of life using the St George's respiratory questionnaire (SGRQ), PImax, hyperinflation indices at rest, such as inspiratory capacity, and at the end of the 6MWT.

\section{Methods}

\section{Study population}

Between March 5, 2014 and September 8, 2016, patients routinely admitted to the rehabilitation programme unit of Centre Hospitalier des Pays de Morlaix (Morlaix, France) were eligible for the study if they had severe or very severe COPD diagnosed according to American Thoracic Society (ATS)/ERS criteria [8] at admission (forced expiratory volume in $1 \mathrm{~s}\left(\mathrm{FEV}_{1}\right)<50 \%$ predicted). Exclusion criteria were previous pneumonectomy or lobectomy in the past 6 months, spontaneous risk of pneumothorax or rib fracture, incapacity to follow a standard rehabilitation programme (locomotor deficits, acute cardiac failure and acute exacerbation of COPD at the beginning of the programme) and the absence of written informed consent. The study was approved by the ethics board (CPP Ouest 6, CPP803, n²013-A01180-45) in December 2013.

\section{Intervention}

At the time of inclusion, patients were randomised to follow a predefined standardised pulmonary rehabilitation programme associated with IMT (IMT group) versus the same standardised pulmonary rehabilitation programme without IMT (control group) for a duration of 4 weeks. Block randomisation was performed by stratum (according to PImax $\leqslant 60 \mathrm{cmH}_{2} \mathrm{O}$ or $>60 \mathrm{cmH}_{2} \mathrm{O}$ ) with variable block sizes. Block sizes were randomly established by the statistician. Investigators were kept blinded to each block size, to ensure that they could not become aware of patients' allocation in advance.

The standardised pulmonary rehabilitation programme (IMT and control groups) was conducted over 4 weeks, 5 days per week and included aerobic exercise on a cycle ergometer and a treadmill (each for 30 min per day) $[9,10]$, strengthening of lower and upper limb muscle groups, a therapeutic educational programme, aerobic gymnastics in groups, a smoking cessation programme and sociopsychological and dietary advice.

In the IMT group, all subjects trained their inspiratory muscles daily during two sessions of 15 min each, supervised by a physiotherapist, five times a week, over 4 weeks. The patients had to breathe slowly with 
an increased tidal volume; after 10 inspirations, they could have a break by breathing at rest for a short time. The cycle of 10 inspirations was repeated 15 times. The inspiratory muscle training was performed using a threshold inspiratory muscle trainer (PowerBreathe Medic; PowerBreathe, Southam, UK) at a resistance generating a pressure corresponding to $50 \%$ of the initial PImax for each session. The intensity was increased $(+10 \%)$ after 10 days of training during the programme to reach $60 \%$ of the initial PImax.

\section{Testing and end-points}

The primary end-point was dyspnoea assessment using the Multidimensional Dyspnoea Profile (MDP) questionnaire [11] after 4 weeks of the rehabilitation programme. The MDP questionnaire was self-administered and performed at the end of the 6MWT.

The secondary end-points were the assessment of dyspnoea using the Borg scale performed at the end of the 6MWT and the modified Medical Research Council (mMRC) scale, assessment of quality of life using the SGRQ and the assessment of the functional changes in PImax measured using a Micro RPM (Micro Medical, Rochester, UK) $[12,13]$ and inspiratory capacity at rest and inspiratory capacity at the end of the 6MWT using a portable spirometer (Spirobank II, MIR Medical International Research, Rome, Italy) [14]. All baseline functional measurements (i.e. FEV1, FEV1/forced vital capacity, total lung capacity (TLC), residual volume, and inspiratory capacity) and two 6MWTs were performed in accordance with international guidelines $[15,16]$.

\section{Sample size}

In order to verify our main objective, we assumed a reduction of at $\geqslant 1$ point by item of the sensory component on the MDP questionnaire with a standard deviation at 2 points for the IMT group in comparison with the control group. Such reduction was extrapolated from results obtained with the commonly used Borg scale [17]. In addition, Меєк et al. [18] reported a standard deviation of $\sim 2$ points for the intensity of the sensory component to demonstrate the validity and reliability of the MDP questionnaire, which is similar to that reported with the Borg scale [7, 17]. For an $\alpha$-error of $5 \%$ and $\beta$-error of $20 \%$, the expected sample size would therefore be 126 patients. In order to anticipate loss to follow-up, 150 patients needed to be included.

\section{Statistical analyses}

All the data were collected by a research nurse blinded to treatment allocation. Continuous variables were expressed as mean $\pm \mathrm{SD}$ if distribution was normal; if not, results were presented as median (interquartile range). The effect of IMT on dyspnoea and functional parameters was analysed using t-tests or Wilcoxon's test (in case of non-normal distribution) for within-group and between-group comparisons, respectively. Correlations were analysed using Spearman's rank correlation coefficient.

All data were analysed in an intention-to-treat analysis. For comparison, a p-value of $<0.05$ was considered as statistically significant. All statistical tests were performed using SAS software (version 9.4; SAS Institute, Cary, NC, USA).

\section{Results}

Between March 5, 2014 and September 8, 2016, 161 severe or very severe COPD patients attended our pulmonary rehabilitation centre. After verification of eligibility criteria, 150 patients were included; one patient who had one non-inclusion criterion was included, but was not randomised, and therefore was not included in the analysis (figure 1). Finally, 149 patients were randomised to a standardised pulmonary rehabilitation programme $(\mathrm{PR} ; \mathrm{n}=75)$ or a standardised pulmonary rehabilitation programme with IMT (PR+IMT; n=74). Three patients had undergone pneumonectomy and three other patients had undergone a lobectomy in the past years before the inclusion ( $>6$ months prior to inclusion in the trial); all were in the control group.

Demographic, clinical and initial spirometric data are reported in table 1. The two groups were comparable except for mean age, which, unexpectedly, was lower in the IMT group. The characteristics of dyspnoea sensation based on the MDP questionnaire are detailed in table 2.

\section{Primary outcome}

At the end of intervention, dyspnoea measured using the MDP questionnaire (sensory component) showed a significant decrease in the PR+IMT (from $14.6 \pm 11.5$ to $9.9 \pm 9.7 ; \mathrm{p}<0.001$ ) and the PR groups (from 14.1 \pm 11.7 to $10.2 \pm 8.6 ; \mathrm{p}=0.04$ ); however, the decrease in dyspnoea was not statistically different between the two groups (table 3 ). 


\section{Secondary outcomes}

At the end of intervention, dyspnoea measured using the Borg or the mMRC scale significantly decreased in the PR+IMT (Borg 5.4 \pm 2.2 to $4.0 \pm 2.1, \mathrm{p}<0.001$; mMRC $2.3 \pm 1.1$ to $1.4 \pm 1.2, \mathrm{p}<0.001$ ) and the PR groups (Borg 5.2 \pm 2.0 to $4.2 \pm 1.8, \mathrm{p}<0.001$; mMRC $2.2 \pm 1.0$ to $1.5 \pm 1.1, \mathrm{p}<0.001$ ); however, the decrease in dyspnoea measured using both scales was not statistically different between the two groups (table 3 ).

At the end of intervention, PImax increased more in the IMT+PR group than in the PR group. In addition, there was a trend towards a correlation between changes obtained after the programme in the PImax and in the difference of inspiratory capacity (difference between effort and rest) or in MDP (table 4). However, improvement of quality of life (SGRQ) was not different between the two groups (table 3). There was no significant difference for any of the other functional parameters, such as 6MWT or hyperinflation (table 3). Furthermore, there was no influence of confounding variables (age, body mass index (BMI), arterial carbon dioxide tension $\left(\mathrm{PaCO}_{2}\right)$, arterial oxygen tension $\left(\mathrm{PaO}_{2}\right)$, BODE (BMI, airflow obstruction, dyspnoea, exercise capacity) index, oxygen therapy, non-invasive ventilation, inhaled treatment and chronic heart failure) on the primary end-point (data not shown).

Finally, no heterogeneity was observed between predefined strata; particularly, no added benefit of IMT during pulmonary rehabilitation was observed in the subgroup of patients with $P$ Imax $\leqslant 60 \mathrm{cmH}_{2} \mathrm{O}$ (online supplementary table S1).

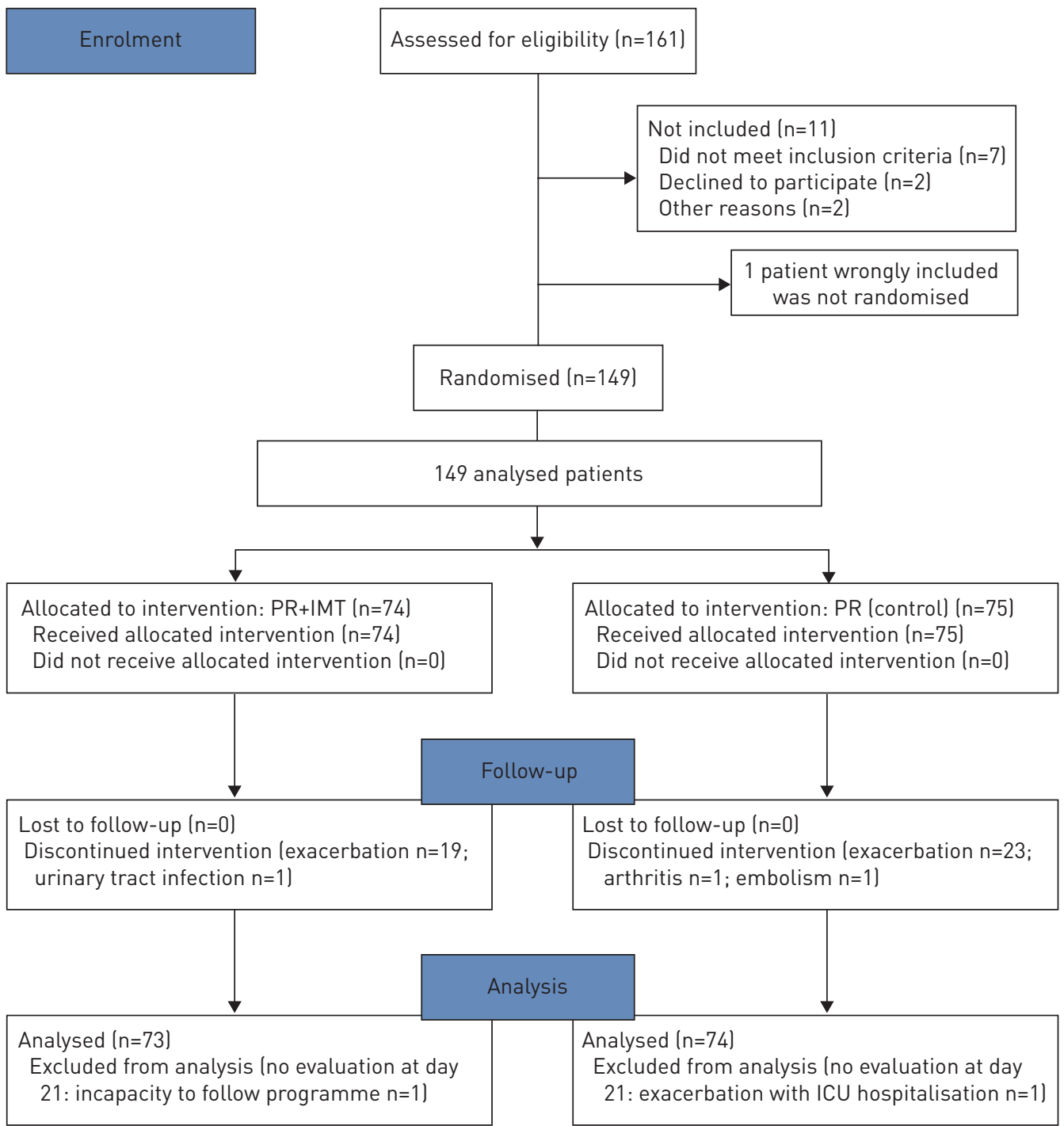

FIGURE 1 CONSORT (Consolidated Standards of Reporting Trials) 2010 flow diagram. PR: pulmonary rehabilitation; IMT: inspiratory muscle training; ICU: intensive care unit. 
In addition, post hoc stratification on hyperinflation indexes (i.e. inspiratory capacity $<80 \%$ predicted or $\geqslant 80 \%$ pred [19] and inspiratory capacity/TLC $>25 \%$ or $\leqslant 25 \%$ [20]) showed no significant difference between the two groups in terms of improvement of dyspnoea (measured using the MDP questionnaire, mMRC dyspnoea scale and Borg scale), quality of life (SGRQ) or 6-min walking distance (6MWD) (online supplementary tables S2 and S3).

\section{Discussion}

In this randomised controlled trial investigating the effect of IMT during a pulmonary rehabilitation programme with a pulmonary rehabilitation programme without IMT in severe or very severe COPD patients, dyspnoea was improved in the two groups but change in dyspnoea was not found to be different between the two groups, even in the subgroup of patients with an inspiratory muscle weakness (PImax $\leqslant 60 \mathrm{~cm} \mathrm{H}_{2} \mathrm{O}$ ). The improvement of quality of life and 6MWD was not statistically different between the two groups. We only observed a significantly higher improvement of PImax in the pulmonary rehabilitation-associated IMT group as compared to the pulmonary rehabilitation group.

In the present study, we assessed the benefit of IMT on dyspnoea using the MDP questionnaire as a primary outcome and other dyspnoea scales (mMRC and Borg scales) as secondary outcomes. The MDP questionnaire was chosen because of its high sensitivity in detecting dyspnoea changes after intervention $[11,18,21,22]$ and for its ability to explore multiple components of dyspnoea [23, 24]. We found a decrease of dyspnoea in the two groups using the MDP questionnaire, Borg scale at the end of the 6MWT or mMRC scale. However, we found no difference between the two groups in terms of improvement of MDP questionnaire, Borg scale or mMRC scale in the overall study population or in the predefined subgroups, despite a higher PImax improvement in the IMT group as compared to the non-IMT group. These results are in accordance with other studies. 10 studies compared IMT (using a threshold device) performed during pulmonary rehabilitation versus pulmonary rehabilitation alone; however, only four of these studies used dyspnoea as the main outcome [7, 25-33]. If an improvement in dyspnoea was found after pulmonary rehabilitation with or without IMT, the magnitude of dyspnoea improvement was not

TABLE 1 Baseline patient characteristics and values of the initial tests

\begin{tabular}{|c|c|c|c|}
\hline & IMT group & Control group & p-value \\
\hline Subjects & 74 & 75 & \\
\hline Female/male & $30 / 44$ & $25 / 50$ & 0.362 \\
\hline Age years & $62.2 \pm 8.0$ & $65.9 \pm 8.9$ & $0.009^{\#}$ \\
\hline $\mathrm{BMI} \mathrm{kg} \cdot \mathrm{m}^{-2}$ & $26.2 \pm 5.9$ & $24.7 \pm 5.9$ & 0.128 \\
\hline Oxygen therapy & 36 & 37 & 0.933 \\
\hline NIV & 18 & 24 & 0.298 \\
\hline GOLD stage 3 & 37 & 32 & 0.369 \\
\hline GOLD stage 4 & 37 & 43 & \\
\hline FEV1 \% pred & $36.4 \pm 9.5$ & $34.2 \pm 8.4$ & 0.139 \\
\hline FEV $1 / V C \%$ & $0.6 \pm 0.1$ & $0.6 \pm 0.1$ & 0.595 \\
\hline RV \% pred & $210.7 \pm 58.7$ & $211.1 \pm 82.2$ & 0.975 \\
\hline TLC \% pred & $123.5 \pm 21.2$ & $123.0 \pm 32.5$ & 0.923 \\
\hline $\mathrm{P}_{\max } \mathrm{CmH}_{2} \mathrm{O}$ & $66.2 \pm 21.7$ & $64.8 \pm 23.0$ & 0.691 \\
\hline PImax \% pred & $76.5 \pm 24.4$ & $77.1 \pm 24.8$ & 0.891 \\
\hline mMRC dyspnoea score & $2(2-3)$ & $2(2-3)$ & 0.741 \\
\hline SGRQ-T & $53.5 \pm 13.8$ & $56.4 \pm 14.9$ & 0.235 \\
\hline SGRQ-S & $58.9 \pm 21.5$ & $58.3 \pm 21.8$ & 0.860 \\
\hline SGRQ-A & $71.1 \pm 17.2$ & $74.9 \pm 16.4$ & 0.172 \\
\hline SGRQ-I & $41.6 \pm 14.9$ & $45.2 \pm 18.9$ & 0.197 \\
\hline 6MWD m & $386.6 \pm 111.7$ & $373.1 \pm 96.0$ & 0.430 \\
\hline 6MWD \% pred & $59.7 \pm 15.6$ & $58.0 \pm 13.0$ & 0.459 \\
\hline $\mathrm{PaO}_{2} \mathrm{mmHg}$ & $67.9 \pm 9.1$ & $68.1 \pm 9.5$ & 0.906 \\
\hline $\mathrm{PaCO}_{2} \mathrm{mmHg}$ & $43.1 \pm 6.7$ & $45.2 \pm 6.7$ & 0.069 \\
\hline \multicolumn{4}{|c|}{$\begin{array}{l}\text { Data are presented as } \mathrm{n}, \text { mean } \pm \text { SD or median (interquartile range), unless otherwise stated. IMT inspiratory } \\
\text { muscle training; BMI: body mass index; NIV: non-invasive ventilation; GOLD: Global Initiative for Chronic } \\
\text { Obstructive Lung Disease; FEV1: forced expiratory volume in } 1 \mathrm{~s} ; \% \text { pred: } \% \text { predicted; VC: vital capacity; } \\
\text { RV: residual volume; TLC: total lung capacity; PImax: maximal inspiratory pressure; mMRC: modified } \\
\text { Medical Research Council; SGRQ: St George's Respiratory Questionnaire; T: total; S: symptoms; A: activity; } \\
\text { I: impact; } 6 \mathrm{MWD:} \mathrm{6-min} \mathrm{walking} \mathrm{distance;} \mathrm{PaO}_{2} \text { : arterial oxygen tension; } \mathrm{PaCO}_{2} \text { : arterial carbon dioxide } \\
\text { tension. \# } \mathrm{p}<0.05 \text {. }\end{array}$} \\
\hline
\end{tabular}


found to be statistically different between patients who had pulmonary rehabilitation with IMT and those who had pulmonary rehabilitation only $[7,27,28]$. These observations are consistent with those of a recent meta-analysis [6]. We found no heterogeneity in strata analysis, particularly according to whether patients had PImax $\leqslant 60 \mathrm{cmH}_{2} \mathrm{O}$ or $>60 \mathrm{cmH}_{2} \mathrm{O}$ (online supplementary table $\mathrm{S} 1$ ). Finally, there was a significant clinical improvement of quality of life in the two groups (SGRQ-total from $53.5 \pm 13.8$ to $43.9 \pm 13.5, \mathrm{p}<0.001$ for the PR+IMT group and from $56.4 \pm 14.9$ to $47.2 \pm 14.5$ for the PR group alone), as described in other studies $[5,6]$. Moreover, there was no difference in improvement of quality of life between the groups. Thus, our results support the general statement of the ATS/ERS consensus on key concepts in pulmonary rehabilitation [1] that mention that the addition of IMT to pulmonary rehabilitation was questionable. In addition, our results do not support the ATS/ERS [1] and Société de Pneumologie de Langue Française [34] consensus that recommend adding IMT to a pulmonary rehabiltation programme if patients present an objective weakness of inspiratory muscles ( $P$ Imax $\leqslant 60 \mathrm{cmH}_{2} \mathrm{O}$ ); this statement was based on one meta-analysis [4] and not on randomised controlled trials evaluating IMT in COPD patients with or without inspiratory muscle weakness [4].

PImax increased in both groups, but change in PImax was greater in the PR+IMT group $\left(+14.8 \mathrm{cmH}_{2} \mathrm{O}\right)$ than in the PR group $\left(+9.9 \mathrm{cmH}_{2} \mathrm{O}, \mathrm{p}=0.04\right)$. The magnitude of $P$ Imax increase following IMT is consistent with changes reported by Gosselink et al. [6] $\left(+13 \mathrm{cmH}_{2} \mathrm{O}\right)$. However, despite a statistically significant difference between the two groups for PImax, dynamic hyperinflation was not different between groups. This was confirmed by the low correlation between change in PImax and change in dynamic hyperinflation at effort. The underlying hypothesis was that IMT could increase diaphragmatic velocity by increasing type II fibres [35], allowing a shorter inspiratory time [36] and a greater expiratory time, which could decrease hyperinflation (translated into changes in inspiratory capacity at effort) [37, 38]. Thus by increasing PImax, IMT may decrease dynamic hyperinflation in severe COPD patients, and consequently dyspnoea. In a prior study [7], we found a similar trend towards an improvement of dyspnoea with IMT in the subgroup of severe COPD patients. In the present study, we found no significant improvement of dynamic hyperinflation evaluated with difference of inspiratory capacity at rest and at effort between the beginning and the end of the programme for PR and PR+IMT groups $(0.3 \pm 0.6$ to $0.4 \pm 0.5, \mathrm{p}=0.087$ and $0.5 \pm 0.5$ to $0.6 \pm 0.5, \mathrm{p}=0.35$, respectively). These results do not confirm those obtained in our previous study. We did not evaluate dynamic hyperinflation for a given level, because patients improved their 6MWD. This could have slightly decreased the sensitivity to detect improvement in dynamic hyperinflation. Dynamic hyperinflation and deconditioning are major causes of dyspnoea [39, 40]. From the available data, exercise training does not have a direct effect on dynamic hyperinflation [41], but reduces ventilatory needs for a given level of exertion [41-43], and this is attributable to breathing pattern modification [43]. Therefore, pulmonary rehabilitation can improve dyspnoea by increasing exercise

TABLE 2 Baseline characteristics of dyspnoea sensation, measured using the Borg scale, multidimensional dyspnoea profile (MDP) questionnaire and the modified Medical Research Council (mMRC) scale

\begin{tabular}{lccc} 
& IMT group & Control group & p-value \\
\hline Subjects & 74 & 75 & \\
mMRC & $2(2-3)$ & $2(2-3)$ & 0.741 \\
Borg lat end of the 6MWT) & $5.4 \pm 2.2$ & $5.2 \pm 2.0$ & 0.522 \\
MDP questionnaire lat end of the 6MWT) & & & \\
Unpleasantness & $4.1 \pm 2.5$ & $4.1 \pm 2.5$ & 0.873 \\
Sensory intensity & $14.6 \pm 11.5$ & $14.1 \pm 11.7$ & 0.814 \\
Muscle work/effort & $2.8 \pm 2.9$ & $3.2 \pm 2.7$ & 0.497 \\
Not enough air/smothering/air hunger & $3.1 \pm 3.1$ & $2.8 \pm 3.1$ & 0.674 \\
Tight/constricted & $1.9 \pm 2.7$ & $1.9 \pm 2.5$ & 0.904 \\
Mental effort/concentration & $3.0 \pm 3.2$ & $2.6 \pm 2.9$ & 0.453 \\
Breathing a lot (rapid/deep/heavyl & $3.8 \pm 3.0$ & $3.7 \pm 3.1$ & 0.813 \\
Depression & $0.6 \pm 1.7$ & $0.6 \pm 1.5$ & 0.893 \\
Anxiety & $1.1 \pm 2.1$ & $1 \pm 1.8$ & 0.737 \\
Frustration & $1.5 \pm 2.8$ & $1.3 \pm 2.3$ & 0.617 \\
Anger & $1.0 \pm 2.2$ & $0.6 \pm 1.6$ & 0.177 \\
Fear & $0.5 \pm 1.6$ & $0.7 \pm 1.5$ & 0.476 \\
\hline
\end{tabular}

Data are presented as $n$, median (interquartile range), or mean $\pm \mathrm{SD}$, unless otherwise stated. IMT: inspiratory muscle training; 6MWT: 6-min walk test. 
TABLE 3 Change (after minus before intervention) in dyspnoea sensation and functional parameters at the end of the 6-min walk test (6MWT) after intervention (Multidimensional Dyspnoea Profile (MDP) and Borg scales)

\begin{tabular}{|c|c|c|c|}
\hline & IMT group & Control group & p-value \\
\hline Subjects $n$ & 74 & 75 & \\
\hline \multicolumn{4}{|l|}{ Dyspnoea scales } \\
\hline Borg scale & $-1.4 \pm 2.0$ & $-1.0 \pm 1.9$ & 0.160 \\
\hline mMRC & $-0.9 \pm 1.2$ & $-0.8 \pm 1.3$ & 0.508 \\
\hline \multicolumn{4}{|l|}{ MDP questionnaire } \\
\hline Unpleasantness & $-0.4 \pm 2.4$ & $-0.8 \pm 2.4$ & 0.382 \\
\hline Sensory intensity & $-4.6 \pm 10.5$ & $-3.6 \pm 11.0$ & 0.549 \\
\hline Muscle work/effort & $-0.7 \pm 2.9$ & $-0.9 \pm 3.1$ & 0.700 \\
\hline Not enough air/smother/air hunger & $-1.2 \pm 3.3$ & $-1.0 \pm 2.6$ & 0.637 \\
\hline Tight/constricted & $-0.6 \pm 2.8$ & $-0.4 \pm 2.4$ & 0.597 \\
\hline Mental effort/concentrate & $-1.0 \pm 2.9$ & $-0.6 \pm 2.9$ & 0.360 \\
\hline Breathing a lot (rapid/deep/heavy) & $-1.0 \pm 2.8$ & $-0.7 \pm 3.4$ & 0.473 \\
\hline Depression & $-0.3 \pm 1.9$ & $-0.2 \pm 1.1$ & 0.625 \\
\hline Anxiety & $-0.0 \pm 2.4$ & $-0.2 \pm 1.6$ & 0.659 \\
\hline Frustration & $-0.6 \pm 2.3$ & $-0.6 \pm 2.2$ & 0.982 \\
\hline Anger & $-0.2 \pm 2.7$ & $-0.1 \pm 1.6$ & 0.732 \\
\hline Fear & $0.1 \pm 2.5$ & $-0.2 \pm 1.4$ & 0.292 \\
\hline \multicolumn{4}{|l|}{ SGRQ } \\
\hline Total & $-10.1 \pm 10.9$ & $-9.0 \pm 12.5$ & 0.580 \\
\hline Symptoms & $-4.8 \pm 15.1$ & $-3.4 \pm 14.8$ & 0.581 \\
\hline Activity & $-9.1 \pm 14.7$ & $-10.3 \pm 17.6$ & 0.653 \\
\hline Impact & $-12.1 \pm 13.7$ & $-10.1 \pm 14.7$ & 0.406 \\
\hline \multicolumn{4}{|l|}{ Functional parameters } \\
\hline$P I \max \mathrm{cmH}_{2} \mathrm{O}$ & $14.8 \pm 14.9$ & $9.9 \pm 13.8$ & $0.041^{\#}$ \\
\hline$I C$ at rest $L$ & $0.1 \pm 0.5$ & $0.2 \pm 0.4$ & 0.404 \\
\hline IC at end of 6MWT L & $0.0 \pm 0.5$ & $0.0 \pm 0.7$ & 0.796 \\
\hline IC at end of 6MWT - at rest $L$ & $-0.1 \pm 0.6$ & $-0.2 \pm 0.7$ & 0.525 \\
\hline 6MWD m & $23.4 \pm 51.2$ & $36.2 \pm 44.9$ & 0.111 \\
\hline \multicolumn{4}{|c|}{$\begin{array}{l}\text { Data are presented as mean } \pm \text { SD, unless otherwise stated. IMT: inspiratory muscle training; mMRC: } \\
\text { modified Medical Research Council; SGRQ: St George's Respiratory Questionnaire; PImax: maximal } \\
\text { inspiratory pressure; IC: inspiratory capacity; 6MWD: } 6 \text {-min walking distance. \#: } p<0.05 \text {. }\end{array}$} \\
\hline
\end{tabular}

capacity and decreasing deconditioning $[44,45]$. Our results might therefore be interpreted in the same way as those of SPRUIT et al. [1] specifying that "because whole-body exercise training confers substantial improvements in health-related quality of life, it seems that detecting further improvement using IMT is difficult". Despite the increase in PImax, there was no difference for the items "muscle work/effort" and "mental effort/concentration" of the MDP questionnaire.

TABLE 4 Correlation between inspiratory capacity (IC) and maximal inspiratory pressure (PImax)

\begin{tabular}{|c|c|c|c|c|}
\hline & $\Delta P_{\max }$ & Subjects $\mathrm{n}$ & $\Delta \mathrm{MDP}$ & Subjects $n$ \\
\hline \multicolumn{5}{|l|}{ All patients } \\
\hline$\Delta \mathrm{IC}$ at rest & 0.152 & 146 & -0.259 & 146 \\
\hline$\Delta(\mathrm{IC}$ effort $-\mathrm{IC}$ at rest $)$ & -0.005 & 132 & & \\
\hline \multicolumn{5}{|l|}{ Control group } \\
\hline$\Delta \mathrm{IC}$ at rest & 0.152 & 74 & -0.326 & 74 \\
\hline$\Delta(I C$ effort $-I C$ at rest $)$ & 0.036 & 65 & & \\
\hline \multicolumn{5}{|l|}{ IMT group } \\
\hline$\Delta \mathrm{IC}$ at rest & 0.178 & 72 & -0.207 & 72 \\
\hline$\Delta(\mathrm{IC}$ effort $-\mathrm{IC}$ at rest $)$ & -0.058 & 67 & & \\
\hline
\end{tabular}

$\Delta$ : difference between the beginning and the end of the programme; MDP: multidimensional dyspnoea profile; IMT: inspiratory muscle training. 
Our study has some limitations. First, the method (threshold inspiratory training, $50-60 \%$ of $P \operatorname{Imax}$ ) is in line with recommendations [5]; however, this programme only lasted 4 weeks, whereas studies included in the meta-analysis by Gosselink et al. [5] lasted 1-4 months. Nevertheless, we observed a similar increase in PImax [5]. Therefore, we do not think this factor could affect the results. Second, patients improved their 6MWD between the beginning and the end of the programme; therefore, dyspnoea is not evaluated at the same level of effort. Although it is inherent to the 6MWT, this may be a limit of this study. Last, only six patients with lobectomy or pneumonectomy, all in the control group, were included in our study. Thoracic mechanics differ between patients with an obstructive disease and those with a mixed impairment (i.e. obstructive and restrictive defects) and the effect of IMT on PImax change might be different; however, this could not be determined in our study.

The strengths of our study are 1) the use of a randomised design; 2) a well predefined and standardised rehabilitation programme that was administered for all entering patients; 3 ) a predefined and standardised protocol for IMT rehabilitation and the use of predefined objective end-points that were performed and measured according to international guidelines [1,2,12]; and 4) blinded data collection. Finally, to our knowledge, our study is the largest randomised trial having evaluated the potential benefit of IMT during pulmonary rehabilitation in severe and very severe COPD patients.

In conclusion, in severe or very severe COPD patients, pulmonary rehabilitation with IMT was not found to be superior to pulmonary rehabilitation without IMT in terms of dyspnoea, quality of life or exercise capacity (6MWD) improvement, despite a significantly higher improvement of PImax in the IMT group. The level of the initial PImax $\left(\leqslant 60 \mathrm{cmH}_{2} \mathrm{O}\right.$ or $\left.>60 \mathrm{cmH}_{2} \mathrm{O}\right)$ did not change these results.

\section{References}

1 Spruit MA, Singh SJ, Garvey C, et al. An official American Thoracic Society/European Respiratory Society statement: key concepts and advances in pulmonary rehabilitation. Am J Respir Crit Care Med 2013; 188: e13-e64.

2 Nici L, Donner C, Wouters E, et al. American Thoracic Society/European Respiratory Society statement on pulmonary rehabilitation. Am J Respir Crit Care Med 2006; 173: 1390-1413.

3 Troosters T, Gosselink R, De Paepe K, et al. Pulmonary rehabilitation improves survival in COPD patients with a recent severe acute exacerbation. Am J Respir Crit Care Med 2002; 165: A16.

4 Lötters F, van Tol B, Kwakkel G, et al. Effects of controlled inspiratory muscle training in patients with COPD: a meta-analysis. Eur Respir J 2002; 20: 570-577.

5 Geddes EL, O’Brien K, Reid WD, et al. Inspiratory muscle training in adults with chronic obstructive pulmonary disease: an update of a systematic review. Respir Med 2008; 102: 1715-1729.

6 Gosselink R, De Vos J, van den Heuvel SP, et al. Impact of inspiratory muscle training in patients with COPD: what is the evidence? Eur Respir J 2011; 37: 416-425.

7 Beaumont M, Mialon P, Le Ber-Moy C, et al. Inspiratory muscle training during pulmonary rehabilitation in chronic obstructive pulmonary disease: a randomized trial. Chron Respir Dis 2015; 12: 305-312.

8 Vestbo J, Hurd SS, Agustí AG, et al. Global strategy for the diagnosis, management and prevention of chronic obstructive pulmonary disease, GOLD executive summary. Am J Respir Crit Care Med 2013; 187: 347-365.

9 Préfaut C, Ninot G. La Réhabilitation du Malade Respiratoire Chronique. Issy les Moulineaux, Elsevier Masson, 2009.

10 Reychler G, Roeseler J, Delguste P. Kinésithérapie Respiratoire. 3rd Edn. Issy les Moulineaux, Elsevier Masson, 2014.

11 Banzett RB, O'Donnell CR, Guilfoyle TE, et al. Multidimensional Dyspnea Profile: an instrument for clinical and laboratory research. Eur Respir J 2015; 45: 1681-1691.

12 American Thoracic Society/European Respiratory Society. ATS/ERS statement on respiratory muscle testing. Am J Respir Crit Care Med 2002; 166: 518-624.

13 Hautmann $\mathrm{H}$, Hefele S, Schotten K, et al. Maximal inspiratory mouth pressures (PIMAX) in healthy subjects what is the lower limit of normal? Respir Med 2000; 94: 689-693.

14 Liistro G, Vanwelde C, Vincken W, et al. Technical and functional assessment of 10 office spirometers: a multicenter comparative study. Chest 2006; 130: 657-665.

15 Miller MR, Hankinson J, Brusasco V, et al. Standardisation of spirometry. Eur Respir J 2005; 26: 319-338.

16 American Thoracic Society. ATS statement: guidelines for the six-minute walk test. Am J Respir Crit Care Med 2002; 166: 111-117.

17 Koppers RJH, Vos PJE, Boot CRL, et al. Exercise performance improves in patients with COPD due to respiratory muscle endurance training. Chest 2006; 129: 886-892.

18 Meek PM, Banzett R, Parshall MB, et al. Reliability and validity of the multidimensional dyspnea profile. Chest 2012; 141: 1546-1553.

19 O’Donnell DE, Revill SM, Webb KA. Dynamic hyperinflation and exercise intolerance in chronic obstructive pulmonary disease. Am J Respir Crit Care Med 2001; 164: 770-777.

20 Casanova C, Cote C, de Torres JP, et al. Inspiratory-to-total lung capacity ratio predicts mortality in patients with chronic obstructive pulmonary disease. Am J Respir Crit Care Med 2005; 171: 591-597.

21 Banzett RB, Pedersen SH, Schwartzstein RM, et al. The affective dimension of laboratory dyspnea: air hunger is more unpleasant than work/effort. Am J Respir Crit Care Med 2008; 177: 1384-1390.

22 Lansing RW, Gracely RH, Banzett RB. The multiple dimensions of dyspnea: review and hypotheses. Respir Physiol Neurobiol 2009; 167: 53-60.

23 Parshall MB, Schwartzstein RM, Adams L, et al. An official American Thoracic Society statement: update on the mechanisms, assessment, and management of dyspnea. Am J Respir Crit Care Med 2012; 185: 435-452. 
24 Mahler D, O’Donnell D. Dyspnea: Mechanisms, Measurement, and Management. 3rd Edn. New York, CRC Press, 2014.

25 Dekhuijzen P, Folgering HT, van Herwaarden CL. Target-flow inspiratory muscle training during pulmonary rehabilitation in patients with COPD. Chest 1991; 99: 128-133.

26 Tout R, Tayara L, Halimi M. The effects of respiratory muscle training on improvement of the internal and external thoraco-pulmonary respiratory mechanism in COPD patients. Ann Phys Rehabil Med 2013; 56: 193- 1.

27 Larson JL, Covey MK, Wirtz SE, et al. Cycle ergometer and inspiratory muscle training in chronic obstructive pulmonary disease. Am J Respir Crit Care Med 1999; 160: 500-507.

28 Berry MJ, Adair N, Sevensky K, et al. Inspiratory muscle training and whole-body reconditioning in chronic obstructive pulmonary disease. Am J Respir Crit Care Med 1996; 153: 1812-1816.

29 Weiner P, Azgad Y, Ganam R. Inspiratory muscle training combined with general exercise reconditioning in patients with COPD. Chest 1992; 102: 1351-1356.

30 Goldstein R, De Rosie J, Long S, et al. Applicability of a threshold loading device for inspiratory muscle testing and training in patients with COPD. Chest 1989; 96: 564-571.

31 Heydari A, Farzad M, Ahmadi Hosseini S. Comparing inspiratory resistive muscle training with incentive spirometry on rehabilitation of COPD patients. Rehabil Nurs 2015; 40: 243-248.

32 Wanke T, Formanek D, Lahrmann $\mathrm{H}$, et al. Effects of combined inspiratory muscle and cycle ergometer training on exercise performance in patients with COPD. Eur Respir J 1994; 7: 2205-2211.

33 Majewska-Pulsakowska M, Wytrychowski K, Rożek-Piechura K. The role of inspiratory muscle training in the process of rehabilitation of patients with chronic obstructive pulmonary disease. Adv Exp Med Biol 2016; 7: 47-51.

34 Perez T, Garcia G, Roche N, et al. Société de Pneumologie de Langue Francaise, Recommandation pour la pratique clinique. Prise en charge de la BPCO, mise à jour 2009. [Guidelines for clinical practice. Management of COPD, update 2009.] Rev Mal Respir 2010; 27: 522-548.

35 Ramirez-Sarmiento A, Orozco-Levi M, Guell R, et al. Inspiratory muscle training in patients with chronic obstructive pulmonary disease: structural adaptation and physiologic outcomes. Am J Respir Crit Care Med 2002; 166: 1491-1497.

36 Villafranca C, Borzone G, Leiva A, et al. Effect of inspiratory muscle training with an intermediate load on inspiratory power output in COPD. Eur Respir J 1998; 11: 28-33.

37 Marin J, Carrizo S, Gascon M, et al. Inspiratory capacity, dynamic hyperinflation, breathlessness, and exercise performance during the 6-minute-walk test in chronic obstructive pulmonary disease. Am J Respir Crit Care Med 2001; 163: 1395-1399.

38 O’Donnell DE, Webb KA. Exertional breathlessness in patients with chronic airflow limitation. The role of lung hyperinflation. Am Rev Respir Dis 1993; 148: 1351-1357.

39 O'Donnell DE. Hyperinflation, dyspnea, and exercise intolerance in chronic obstructive pulmonary disease. Proc Am Thorac Soc 2006; 3: 180-184.

40 Guenette JA, Webb KA, O'Donnell DE. Does dynamic hyperinflation contribute to dyspnoea during exercise in patients with COPD? Eur Respir J 2012; 40: 322-329.

41 Dolmage TE, Evans RA, Goldstein RS. Defining hyperinflation as "dynamic": moving toward the slope. Respir Med 2013; 107: 953-958.

42 Porszasz J, Emtner M, Goto S, et al. Exercise training decreases ventilatory requirements and exercise-induced hyperinflation at submaximal intensities in patients with COPD. Chest 2005; 128: 2025-2034.

43 Puente-Maestu L, Abad YM, Pedraza F, et al. A controlled trial of the effects of leg training on breathing pattern and dynamic hyperinflation in severe COPD. Lung 2006; 184: 159-167.

44 Lacasse Y, Goldstein R, Lasserson TJ, et al. Pulmonary rehabilitation for chronic obstructive pulmonary disease. Cochrane Database Syst Rev 2006; 4: CD003793.

45 McCarthy B, Casey D, Devane D, et al. Pulmonary rehabilitation for chronic obstructive pulmonary disease. Cochrane Database Syst Rev 2015; 2: CD003793. 